\title{
Objectivity and the neutral expert
}

\section{Parascandola}

\section{Objective science should not be without values}

D ebate over whether mammography screening saves lives has become front page news again in recent months. The opening salvo came in October 2001 from Gotzsche and Olsen, who argued in the Lancet that five of the seven randomised trials of screening mammography were of poor or flawed quality and that the remaining two fail to show that the benefits outweigh the risks. ${ }^{1}$ In the US, scientific experts remain divided in their recommendations regarding the benefits of mammography for women in their 40s, although the practice has been strongly defended by political leaders. ${ }^{2}$ This controversy, like many in the realm of disease prevention, raises an important question: when science is uncertain, what else drives an individual investigator's interpretation of the evidence?

In the midst of a public debate over prevention recommendations, it often seems that even in the best of circumstances (that is, when there is a randomised clinical trial) there is little objective knowledge to be found. Indeed, prevention science is frequently charged with being subjective and value laden. The investigator's scientific judgment may be polluted by influences other than the evidence itself. The list of suspected polluters is long, including commitment to a favourite theory, type of training (physician, epidemiologist, biologist), personal habits (smoking, diet), concern about the financial costs of screening, and attitudes towards balancing false positives versus false negatives, to name just a few.

Such influences seem to threaten traditional notions of scientific objectivity. At the start of the scientific revolution in the 17th century, the character of a scientist was believed to be as important as any experimental technique. A scientist, it was believed, should exhibit selflessness, disinterestedness, and a willingness to change her views. ${ }^{3}$ In other words, the scientific investigator should be a neutral observer with no personal interest in their theories or results. Today, in comparison, we are somewhat jaded. No one claims that scientists can be wholly objective and impervious to outside influences, but, at the same time, few of us are willing to give up on scientific objectivity.

Some epidemiologists have responded to this challenge by insisting that individual investigators try, as much as possible, to insulate their scientific work from the realm of policy making. ${ }^{45}$ They urge that investigators should not be active in influencing policy when they are conducting conducting scientific research on a related topic. In other words, they should try to be neutral and disinterested towards their research conclusions. Thus, a researcher who advocates for legislation requiring insurers to pay for mammography should not conduct a meta-analysis or write a review of clinical trials on the effectiveness of mammography. By separating policy (and morality and politics) from science, the argument goes, objectivity will be enhanced. This idea has previously drawn support in other scientific disciplines that are prone to scientific controversy. For example, in the 1920s, when social scientists were accused of being political and unscientific, sociologist Max Weber responded by warning his colleagues: "It is the duty of the man of science to remain silent ... on value questions upon which he is so freely encouraged to expound."

However, others have responded that values cannot be isolated from the conduct of research, because many scientific theories and practices themselves are based on value judgments rather than empirical data and epidemiologists actually carry a professional obligation to participate in policy decisions. ${ }^{78} \mathrm{His}$ torians and sociologists of science have marshalled much evidence to support this view, demonstrating how implicit individual prejudice can drive scientific debates.

Rigorous methods are frequently touted as the best means of preserving objectivity, but they are no panacea. The ascent of the randomised controlled trial as the gold standard for testing new treatments was driven by a need for objective assessments of the claims of drug manufacturers. ${ }^{10} \mathrm{R}$ A Fisher originally touted randomisation as the only means of generating an objective measurement of the risk of inferential error. ${ }^{11}$ However, as the mammography debate vividly illustrates, even a randomised controlled trial (or seven) is not sufficient to enforce objectivity. The methodological benefits of randomisation apply only to a single study and not to the synthesis of evidence from several studies. In contrast, the practice of causal inference, for example, entails implicit judgments and choices on the part of investigators, and our methods here are underdeveloped. ${ }^{12}$ Evidential synthesis, as in a meta-analysis, is the most important stage in the scientific process for developing prevention recommendations. We should certainly heed calls for more robust methodologies for evidential synthesis, as methods are essential, if not sufficient, for objective science. However, at the same time, we can benefit from a fuller understanding of the role of values in the interpretation of scientific findings.

Most importantly, we ought to distinguish between objectivity at the level of the individual and objectivity at the level of the scientific community. If objective science can be achieved at all, it will be at the level of the scientific community. For example, the peer review process, that cornerstone of quality science, provides oversight aimed at the community level. It is not the neutrality of individual investigators that keeps us honest, but the diversity of opinions and critical outlook of the scientific community as a whole. In fact, adversarial debate about methodology, and about values, drives advocates to marshal stronger evidence and clarify their reasoning. It is because opinions of the value of mammography differ that randomised trials and rigorous data analyses have been pursued. Thus, individual neutrality is not the key to objective science.

Moreover, values themselves are not always subjective or a matter of individual inclination. Values can be held by individuals or pursued by the scientific community as a whole. Those who insist that values are dangerous to scientific objectivity tend to focus on those values belonging to the individual, such as individual ideological allegiances. ${ }^{5}{ }^{6}$ But the scientific community also pursues common values, such as truth, simplicity, and explanatory power, which are constitutive of scientific activity as we know it. ${ }^{13}$ Additionally, epidemiologists follow common ethical values in their professional practice. ${ }^{14}$ Such values are fundamental to the practice of science and ought not be isolated from it. In fact, much more could be done to incorporate them into daily scientific practice.

As prevention science is currently in the hot seat, we should resist the temptation to retreat to a position of neutrality, otherwise we run the risk of losing the rationale for doing research at all. Not only is neutrality an unrealistic goal, it is an undesirable one. While the debate over mammography is unlikely to be resolved soon, avoiding the policy implications and values behind it will not resolve it any sooner.

J Epidemiol Community Health 2003;57:3-4 


\section{Author's affiliations}

M Parascandola, National Cancer Institute

6130 Executive Blvd, Suite 3109, Bethesda,

MD 20892, USA

Correspondence to: Dr M Parascandola; paramark@mail.nih.gov

\section{REFERENCES}

1 Olsen O, Gotzsche PC. Cochrane review on screening for breast cancer with mammography. Lancet 2001;358:1340-2

2 Marshall E. Battle heats up over

mammography benefits. Science 2002;295:1624-5
3 Shapin S. A social history of truth: civility and science in seventeenth-century England. Chicago: University of Chicago Press, 1994.

4 Rothman KJ, Adami HO, Trichopoulos D Should the mission of epidemiology include the eradication of poverty? Lancet 1998;352:810-13.

5 Savitz DA, Poole C, Miller WC. Reassessing the role of epidemiology in public health. Am J Public Health 1999;89: 1158-61.

6 Proctor RN. Value-free science? Purity and power in modern knowledge. Cambridge, MA: Harvard University Press, 1991:149.

7 Wing S. Whose epidemiology, whose health? Int J Health Serv 1998;28:241-52.

8 Weed DL, Mink PJ. Roles and responsibilities of epidemiologists. Ann Epidemio 2002;12:67-72.
9 Collins H, Pinch T. The Golem: What you should know about science. 2nd edn. Cambridge: Cambridge University Press, 1998.

10 Matthews JR. Quantification and the quest for medical certainty. Princeton: Princeton University Press, 1995

11 Fisher RA. The design of experiments. Edinburgh: Oliver and Boyd, 1935.

12 Weed DL, Gorelic LS. The practice of causal inference in cancer epidemiology. Cancer Epidemiol Biomarkers Prev 1996;5:303-11.

13 Longino HE. Science as social knowledge: values and objectivity in scientific inquiry. Princeton: Princeton University Press, 1990.

14 Weed DL, Coughlin SS. New ethics guidelines for epidemiology: background and rationale. Ann Epidemiol 1999;9:277-80.

\section{Science, ethics, and professional public health practice}

\section{L Weed, R E McKeown}

\section{Competing values and obligations}

\section{PUBLIC HEALTH PRACTICE}

At the core of professional public health practice is a promise to help society by preventing disease and promoting health. Public health is a calling, as much an art as it is steeped in scientific theory, method, and evidence. We, the public health professionals, learn theory and practice in the classroom and hone them in experience. We define core values and embrace integrity, prudence, honesty, and trust. We develop standards of excellence and codes of ethics to guide our professional pursuits. ${ }^{12}$ Our practice is a complex blend of acquiring scientific knowledge and participatory policymaking. We study communities and individuals, the healthy as well as those who suffer from disease, injury, malnutrition, and untimely death. We recommend and advocate policies with others, for others, and for ourselves.

Ethics as an academic discipline and as a pragmatic dimension of our daily professional lives offers a conceptual framework and methods for thinking about and improving the practice of public health. Inevitably, we encounter situations marked by tension between competing values and obligations. Of the many problems that require attention, we choose three: evidence to action; the pitfalls and promise of public advocacy, and the balance between individual freedom and the common good.

\section{EVIDENCE TO ACTION}

The scientific knowledge that matters to public health interventions extends from the physical and biological sciences to epidemiology and on to the environmental, social and behavioural sciences. The problem of deciding when to act on the basis of that knowledge is as much synthetic as it is analytic. We collect evidence and use methods, both qualitative and quantitative, for its interpretation. We recommend actions in a climate buffeted about by politics, economics, and religious beliefs.

We cannot act in a vacuum. For primary prevention, we need to know something about how people are exposed, some semblance of a mechanism of action, how well the factor explains disease occurrence, and how that factor is connected to other determinants that make up the complex tapestry of causation. We need to know something about the expected changes in incidence, morbidity or mortality if the factor is removed, how much such interventions cost, the trade offs in risks and benefits, and how well such changes are tolerated by the public and their cultural institutions.

How much do we need to know? We rarely have the luxury of waiting for a complete understanding of causation. With every new shred of evidence we ask the question: now is it time to act? Sometimes the answer is obvious. Other times we swing back and forth on the pendulum of uncertainty. The scholarship of ethics suggests that such judgments are a product of circumstances-including the current scientific evidence-and ethical principles, obligations, guidelines, and maxims. The principles that guide such decisions are multiplying by the hour. Bioethics gave us four: non-maleficence, beneficence, respect for persons, and justice. Twelve so called principles of public health ethics recently appeared. ${ }^{1}$ The precautionary principle suggests that actions should be taken when the evidence is somewhere below that of the unachievable levels of certainty or proof. ${ }^{3}$ But what is the least amount of evidence needed to warrant action to reduce risk, minimise harm, respect the autonomy of others, achieve justice, and maintain the public trust in our profession?

\section{ADVOCACY, OBJECTIVITY, AND VALUES}

As public health professionals we debate the pitfalls and promise of public advocacy. There are those in the profession who warn us away from advocacy in the hope that we can maintain an objective scientific neutrality. But science alone will not get the work of public health done and objectivity is less a characteristic of the scientist than it is the property of scientific methods. Besides, we are obliged to come to the aid of communities. ${ }^{4}$ Thoughtful, just, and reasoned advocacy is as much a part of our practice as is science.

Ultimately we seek balance between the dispassionate description of scientific findings and a persistent plea to use those findings for public health action. Call it finding a balance between the pursuit of truth for its own sake and solidarity with others for whom we advocate. Call it the balance between realism and pragmatism ${ }^{5}$ or between objectivity and subjectivity. Mix in the values that cut across science and its application. That is the second problem for public health professionals.

\section{INDIVIDUAL FREEDOM AND THE COMMON GOOD}

In mission and means, public health strives for healthy communities and for healthy individuals in communities. ${ }^{6} \mathrm{His}-$ torically, even when public health activities were directed to individuals (for example, immunisation), there was a 
dual intent: to protect both the individual and the health of the community. More recently, public health professionals have recognised the importance of focusing on higher levels of societal organisation and broader concepts of health.

There is in public health an inherent tension between the freedom, rights, and desires of the individual and assuring the optimal conditions for well being of the community. With mandatory immunisation, self determination is in conflict with coercion. Chlorination and fluoridation of water inflict an intervention on individuals without consent. Programmes aimed at transforming social conditions, redistribution of resources, changing policies, or influencing lifestyles or cultural values can also threaten individual freedom and autonomy.

One can argue that these examples are merely reasonable trade offs of living in any community. Being a part of society, after all, entails constraints on freedom. Nevertheless, we wonder whether the goods presumed to justify those constraints are valued and shared by the community as a whole, whether some suffer a greater burden while others gain a disproportionate benefit, whether the coercion is so great as to violate fundamental human rights and dignity, whether the risks imposed are sufficiently large as to require voluntary and informed consent, and finally, whether there should be, or can be, something like informed community consent. ${ }^{7-9}$

\section{SUMMARY}

Public health is a multidimensional entity: a complex of concepts and concrete institutions, both quest and practice, a desired goal and a present vocation. Its domain is extensive, stretching horizontally from providing preventive services as a safety net for individuals to promoting the health of communities, and vertically spanning policies, interventions, and research ranging from fundamental physiological processes to the social forces that change society.

It is inevitable that public health professionals will encounter, even engender, tension between competing values and obligations. We have suggested only three areas where tensions seem particularly pressing.

The first is deciding when to act in public health, given a synthesis of the current knowledge gained from applying scientific methods to cells, individuals, communities, and society at large. It is a balancing act between what needs to be known and what needs to be done.

The pursuit of scientific knowledge (value laden as it is) and the dedicated application of what we know to achieve ends we value are both mutually reinforcing and potentially in conflict. Discerning and maintaining the proper balance, especially in the face of diverse personal and public values and political adversity, is the second of our challenges.

The third problem requires us to determine when and whether the presumed goods of promoting health and preventing disease justify constraints on fundamental rights, and to balance closely held individual values of self determination, privacy, and freedom with community values and wellbeing.

We have not proposed how these three areas of ethical tension are resolved. Indeed their resolution in specific cases is the very stuff of ethical reasoning.
What we have hoped to show is that our fundamental commitments as public health professionals impose upon us ethical dilemmas unique to our calling.

J Epidemiol Community Health 2003;57:4-5

\section{Authors' affiliations}

D L Weed, Division of Cancer Prevention, National Cancer Institute, EPS T-41, 6130 Executive Blvd, Bethesda, MD 20892-7105, USA

R E McKeown, Department of Epidemiology and Biostatistics, Norman J Arnold School of Public Health, University of South Carolina, Columbia, SC 29208, USA

Correspondence to: $\operatorname{Dr}$ D L Weed; dw102i@nih.gov

\section{REFERENCES}

1 Public Health Leadership Council and the American Public Health Association. Public Health Code of Ethics. (http:// www.apha.org/codeofethics/ 2002).

2 American College of Epidemiology. American College of Epidemiology Ethics Guidelines. Ann Epidemiol 2000;10:487-97.

3 Horton R. The new new public health of risk and radical engagement. Lancet 1998;352:251-2.

4 Weed DL, Mink P. Roles and responsibilities of epidemiologists. Ann Epidemiol 2002; 12:67-72.

5 Rorty R. Objectivity, relativism, and truth. Cambridge: University Press, 1991

6 Stoto MA, Abel C, Dievler A, eds. Healthy communities: new partnerships for the future of public health. Washington, DC: Institute of Medicine, 1996

7 Callahan D, Jennings B. Ethics and public health: forging a strong relationship. Am J Public Health 2002;92:169-76.

8 Mann JM. Medicine and public health, ethics and human rights. Hastings Cent Rep 1997;27:6-13.

9 Pellegrino ED. Autonomy and coercion in disease prevention and health promotion. Theoret Med 1984;5:83-91.

\section{Self care and consumer health. Do we need a public health ethics?}

\section{D Castiel}

\section{Bioethical principlism is not enough for dealing with global public health issues}

B ioethical principlism places an emphasis on autonomy. In a certain analogous way, modern promotional public health emphasises the role of self care as a key element to achieve healthy states. One of the many presumed available sources of guidance in health is information provided on the internet. Both this information's quality and the tools to measure it are considered highly inconsistent. This topic has become a matter of bioethical concern, because of the possibilities for harm (maleficence) to potential users. On the other hand, there are large contingents worldwide consisting solely of non-consumers unable to dedicate themselves to self care practices. This brief commentary considers some issues related to a global perspective towards what may be considered pertinent to a public health ethics.

The domains of health ethics have been occupied by new issues. Emerging circumstances clearly call for the field's revalidation. One example is the discussion of a so called "global" bioethics, not focused exclusively on problems in the economically strong nations. ${ }^{1}$ Other emerging ethical issues involve "ehealth", or the availability of health related content through electronic information networks. New specialties such as telemedicine and cybermedicine are thus appearing in the area of medical informatics. There are already specialised journals on e-health and literature on corresponding ethical issues.

Under such circumstances it becomes untenable to insist on the traditional 
place of the "patient", who requires the proximity of his/her pair-the "physician"- to be defined as such. Curiously, with the increasing distance in the patient-physician relationship, the patient's place has received new designations. In our opinion, some of these terms are appropriate, including "medical ends user". ${ }^{2}$ Other terms are clearly up for discussion because of their premises, like "e-health consumer"3 and "consumer health informatics". ${ }^{4}$

The contemporary world imposes a difficult test on all those who intend to join to it, by demonstrating adherence and the economic capacity to accompany the unceasing, whimsical trends of market consumerism. Those who fail the test and cannot afford or are denied access to the necessary commodities become nonconsumers or consumer failures. They are incapable of becoming "free", autonomous individuals. ${ }^{5}$ Huge contingents of the world's population live and die in such conditions.

Still, the dominant perspective in the sociopolitical and economic road to be trod by the peoples of the planet seems to be towards globalisation, pursued by monopolistic capitalism in its various facets (especially in the so called postindustrial society, where the services and knowledge production sectors now enjoy economic hegemony).

Health promotion policies place a clear emphasis on autonomy. In general, when dealing with the notion of personal autonomy, we should be clear about the individualist premises underlying the prevailing concept of "person" in the West. Such premises become manifest in self care proposals. There are currently various forms of "healthy self building" through physical activities aimed at risk avoidance (for example, cardiovascular risk), aesthetics (production of a personal appearance with standardised forms of physical beauty and bodily attractiveness), rehabilitation (for the very obese or the middle aged who seek to "feel more fit"), and performance (athletic contests, both amateur and professional).

Certain aspects pertaining to the "fitness" concept deserve special attention. ${ }^{6}$ Without going into the distinctions and imbrications between this concept and that of good health, let us highlight how pertinent it is that health care is also linked to the idea of feeling fit, or feeling physically well disposed.

Subjective feelings of possessing fitness by way of disciplined training are especially important. The quest for fitness imposes a state of frequent and endless training, with ever present self scrutiny and a nagging anxiety over the possibility of "getting out of shape".
Countless men and women currently attempt to keep their bodies ready/ adjusted/in shape to deal with overtly hazardous events like rallies, resistance trials in wilderness areas, $\mathrm{x}$-games, etc. And they also attempt to "keep in shape" for the potentially unexpected events provided by multiple possibilities from a veritable menu of adventures in contemporary life. Yet they must also obviously have the wherewithal to consume the goods and services needed to engage in such activities.

The spread of ideas involving self care and health promotion behaviour is in full swing. A rapid search on Medline will identify a deluge of articles on this issue under the various (and not always clear) terminology that goes with it. This perception was highlighted by Kulbok and associates: they referred to the reigning confusion in the self care/health promotion field. After a critical analysis of the terminology, these authors highlighted the different meanings in the ways by which specialist use ideas and concepts inherent to the area: "health promotion", "health promotion behaviour", "health protection behaviour", "disease prevention behaviour", "preventive health behaviour", "healthy behaviour", and "healthy life style". ${ }^{7}$

New ethical issues and sociocultural repercussions have emerged in both the health care and self care fields through mediations between the electronic media, health professionals, and users, who in turn become agents of consumption. Still, what is to be done with the vast multitude of non-consumers surviving precariously on this planet? How does one deal with issues at the societal level: poverty, inequality, and nutritional and housing deficiencies and their repercussions on illness, violence, crime, and exclusion? Such problems have the same roots as our inability to establish realistic values that are pertinent to living in contemporary times. ${ }^{8}$

Critics of bioethics contend that it is impossible to apply the principles of freedom and autonomy from classic principlist bioethics as instruments for moral conflict mediation in societal settings with great socioeconomic inequality, ${ }^{9}$ where non-consumers also tend to be more vulnerable in terms of health. In this sense the agenda of a global bioethic should also include the analysis, discussion, and development of strategies to deal with social inequalities and the vulnerability of populations that are excluded as agents of consumption. This implies not allowing health related decisions to be made primarily at the private level. ${ }^{10}$
Faced with the question of whether traditional principlist bioethics is sufficient to deal not only with moral dilemmas but also with public health problems, unfortunately our answer cannot be categorically affirmative. We face the important challenge of taking lack of autonomy into consideration as a crucial aspect for building a "public health ethic". Although it may sound like a truism, such an ethic should also include old public health issues on its agenda. It should provide the basic conditions for autonomy (and citizenship) to populations excluded from the markets and consumption through a struggle against the contemporary causes of destitution and ignorance. In particular, it should seek ways to reduce the vulnerability and deep inequalities in the distribution of means for protection, treatment, and rehabilitation of the vast multitudes within the context of the heavy side effects of socioeconomic inequities in the "globalising" economic trends dictated by economically stronger nations. The moral arguments emerging from the confrontation between the large pharmaceutical industry and representatives of economically weaker nations (whether from the public sector or civil society) that resulted in breaking patents on antiretroviral drugs to make them more accessible to people with HIV undeniably belongs to the field of public health ethics.

J Epidemiol Community Health 2003;57:5-6

\section{Author's affiliations}

L D Castiel, National School of Public Health, Oswaldo Cruz Foundation, Rua Leopoldo Bulhões, 1480/802 Rio de Janeiro, Brazil 21041-210

Conflicts of interest: none

Correspondence to: Dr L D Castiel; castiel@ensp.fiocruz.br

\section{REFERENCES}

1 Singer PA. Medical ethics. BM 2000;321:282-5.

2 Ferguson, T. From patients to end users. BM 2002;324:555.

3 Risk A, Dzenowagis J. Review of Internet health information quality initiatives. Journal of Medical Internet Research 2001;3:e28.

4 Eysenbach G, Diepgen TL. The role of e-health and consumer health informatics for evidence-based patient choice in the $21 \mathrm{st}$ century. Clin Dermatol 2001;19:11-17.

5 Bauman Z. Postmodernity and its discontents. Cambridge: Polity Press, 1997.

6 Lupton D. The imperative of health: public health and the regulated body. London: Sage, 1995.

7 Kulbok PA, Baldwin JH, Cox CL, et al. Advancing discourse on health promotion: beyond mainstream thinking. Advanced Nursing Science 1997;20:12-20.

8 Buchanan DR. An ethic for health promotion. Rethinking the sources of human well-being. Oxford: Oxford University Press, 2000

9 Castoriadis $C$. Le cache-misère de l'éthique. Lettre Internationale, 1993;37:2-8

10 Kottow M. Sanitary justice in scarcity. Cadernos de Saúde Pública 1999;15 (suppl 1):43-50. 